\title{
Effects of ankle and knee braces on leg stiffness during hopping
}

\author{
Hiroaki Hobara ${ }^{1 *}$, Yoshiyuki Kobayashi ${ }^{1}$, Tomoya Ueda ${ }^{1,2}$, Masaaki Mochimaru ${ }^{1}$ \\ From 4th Congress of the International Foot and Ankle Biomechanics (i-FAB) Community \\ Busan, Korea. 8-11 April 2014
}

In a spring-mass model (Figure 1-A), the stiffness of the leg spring (leg stiffness; Kleg) is thought to be an important factor in musculoskeletal performance in hopping, running and jumping [1]. Despite the fact that many athletic activities are performed with joint stabilizers, little is known about the Kleg with ankle and/or knee braces. A previous study demonstrated that neither ankle taping nor bracing affected the Kleg during hopping at $3.0 \mathrm{~Hz}$ [2]. However, it remains unclear if this constant $K$ leg exists or changes at other hopping frequencies. The purpose of this study was to more extensively investigate the effect of ankle and knee braces on the Kleg over a range of hopping frequencies.

Ten male participants performed one-legged hopping in place, matching metronome beats at $2.2,2.6$, and $3.0 \mathrm{~Hz}$. $\backslash$ Based on a spring-mass model, we calculated Kleg using an inertial sensor (Myotest ${ }^{\circledR}$, Myotest SA, Switzerland). Commercially-available ankle and knee braces (Ankle Guard-soft and Knee Guard-Ligament3, ALCARE, Japan) were used to constrain these joints, respectively.

Statistical analysis revealed the existence of a significant main effect of hopping frequency $(F(1.22,10.97)=$ 48.16, $p<0.01$; Figure 1-B) on Kleg but no significant main effect of brace conditions $(F(3.00,27.00)=0.15$, $p=0.926)$, nor a significant interaction between hopping frequency and brace conditions $(F(6.00,54.00)=0.94$, $p=0.472$ ) on Kleg. These results indicate that neither ankle nor knee bracing affects the Kleg in a range of hopping frequency.

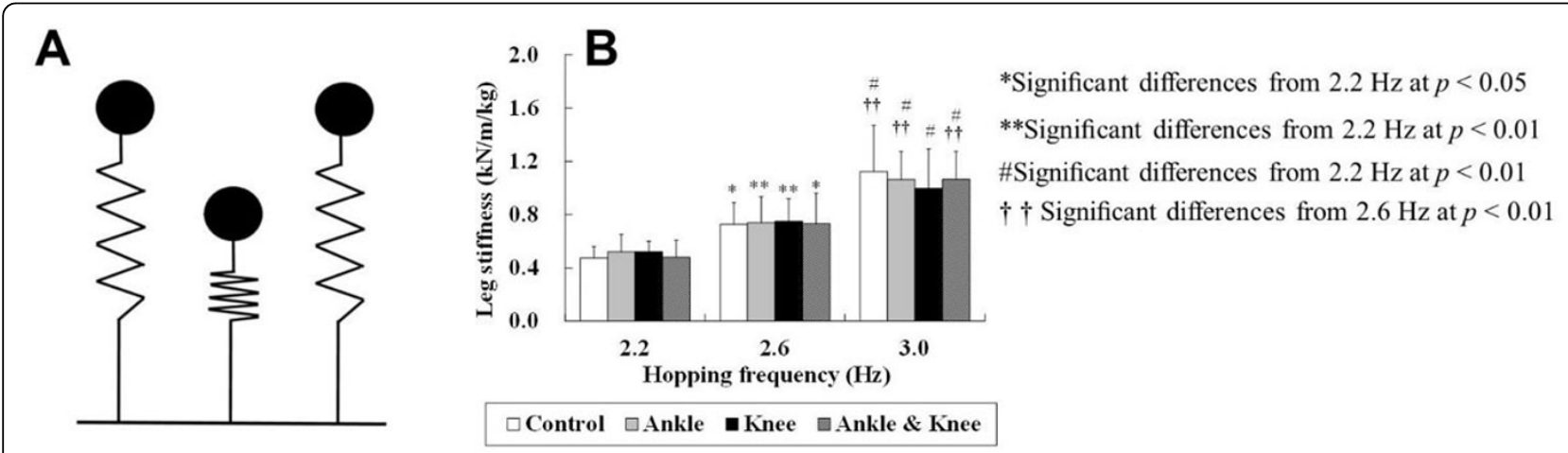

Figure 1 A: Spring-mass model for hopping. This model consists of a body mass and a massless linear spring supporting the body mass. The model is shown at the beginning of the ground contact phase (left), the middle of ground contact phase (middle), and at the end of ground contact phase (right). B: Comparison of Kleg among brace conditions in three hopping frequencies.

\footnotetext{
* Correspondence: hobara-hiroaki@aist.go.jp

${ }^{1}$ National Institute of Advanced Industrial Science and Technology, Tokyo,

135-0064, Japan

Full list of author information is available at the end of the article
} 


\section{Authors' details}

${ }^{1}$ National Institute of Advanced Industrial Science and Technology, Tokyo,

135-0064, Japan. ${ }^{2}$ Tokyo University of Science, Chiba, 278-8510, Japan.

Published: 8 April 2014

\section{References}

1. Butler RJ, et al: Lower extremity stiffness: Implication for performance and injury. Clin Biomech 2003, 18:511-517.

2. Williams $\mathrm{S}$, Riemann BL: Vertical leg stiffness following ankle taping and bracing. Int J Sports Med 2009, 30:383-386.

doi:10.1186/1757-1146-7-S1-A108

Cite this article as: Hobara et al.: Effects of ankle and knee braces on leg stiffness during hopping. Journal of Foot and Ankle Research 2014

7(Suppl 1):A108.

Submit your next manuscript to BioMed Central and take full advantage of:

- Convenient online submission

- Thorough peer review

- No space constraints or color figure charges

- Immediate publication on acceptance

- Inclusion in PubMed, CAS, Scopus and Google Scholar

- Research which is freely available for redistribution

Submit your manuscript at www.biomedcentral.com/submit 